\title{
Aneurysm of the left atrium in a child with patent ductus arteriosus and mitral valve prolapse
}

Aneurisma de átrio esquerdo em criança com persistência do canal arterial e prolapso da valva mitral

\author{
Danielle Lilia Dantas Tukamoto ${ }^{1}$, Carlos Henrique De Marchi ${ }^{1}$, Lilian Beani ${ }^{1}$, Ulisses Alexandre \\ Croti $^{1}$
}

Descriptors: Heart aneurysm. Ductus arteriosus. Mitral valve.

\section{CLINICAL DATA}

Infant 9 months, $6.5 \mathrm{~kg}$, female with history of dyspnea during feeding and poor weight gain. Born at term weighing $3.2 \mathrm{~kg}$. In the first month, was diagnosed with congenital heart disease with increased pulmonary hemodynamic, being the child sent from her hometown for surgical treatment.

Physical examination showed malnutrition with weight below the percentile 3 for age, tachydyspneic, acyanotic and pale. Hyperdynamic precordium with apical impulse deviated to the left and chest bulging to the left. Continuous murmur $3+/ 6+$, with multiple clicks in the left infraclavicular region. Liver $3 \mathrm{~cm}$ from the right costal margin. Large and palpable peripheral pulses in all four limbs.

\section{ELECTROCARDIOGRAM}

Sinus tachycardia with frequency of 150 beats / min, SAQRS $+60^{\circ}$, and atrial and left ventricular (Figure 1).
1. Pediatric Cardiovascular Surgery Service of São José do Rio Preto - Hospital de Base - School of Medicine of São José do Rio Preto, SP, Brazil.

Work performed at the Department of Pediatric Cardiovascular Surgery of São José do Rio Preto - - Hospital de Base - School of Medicine of São José do Rio Preto, SP, Brazil.
Descritores: Aneurisma cardíaco. Canal arterial. Valva mitral.
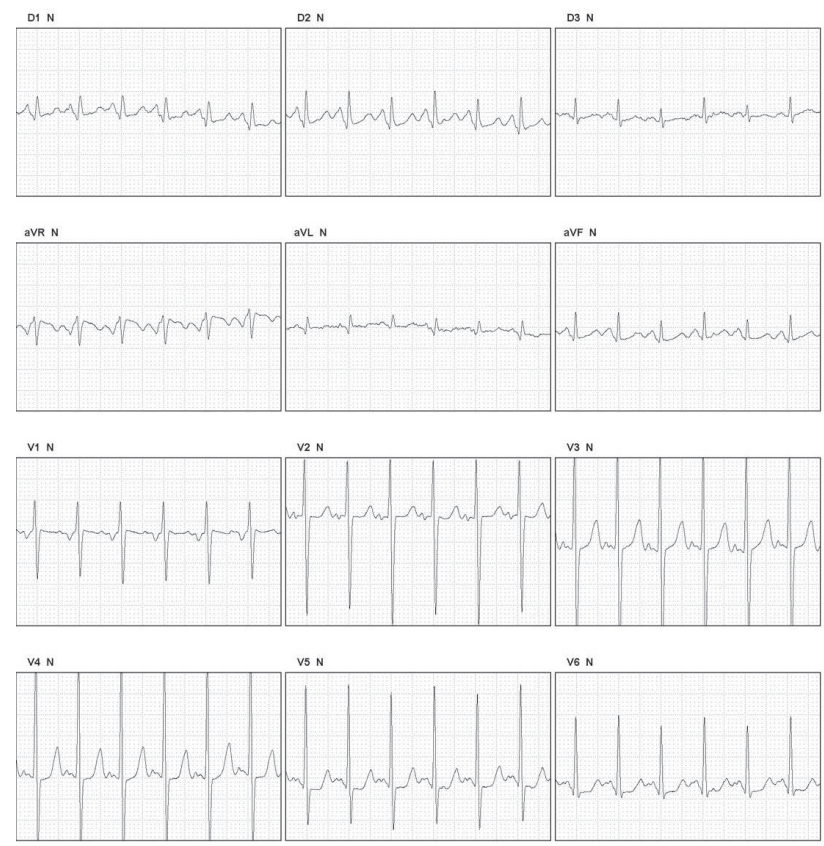

Fig. 1 - Electrocardiogram showed sinus tachycardia, atrial and ventricular overload

Correspondence address: Ulisses Alexandre Croti Hospital de Base - Faculdade de Medicina de São José do Rio Preto FAMERP - Avenida Brigadeiro Faria Lima, 5544

CEP 15090-000 - São José do Rio Preto - SP - Brazil

E-mail: uacroti@uol.com.br

Article received on August $10^{\text {th }}, 2012$ Article accepted on September 17 th, 2012 


\begin{tabular}{|ll|}
\hline Abbreviations, acronyms e symbols \\
\hline bpm & beats per minute \\
PDA & Patent Ductus Arteriosus \\
\hline
\end{tabular}

\section{RADIOGRAPHY}

Enlarged cardiac area, cardiothoracic ratio of 0.61 , an increase of left atrium and left ventricle. Increased pulmonary vascular network (Figure 2).

\section{ECHOCARDIOGRAM}

Patent ductus arteriosus (PDA) with 7.09-mm and 4.48 $\mathrm{mm}$ aortic end in the lung. Mitral valve prolapse with mild to moderate degree. Dilation of the left atrium and moderate dilation of the left ventricle. Preserved ventricular function (Figure 3).

\section{A}

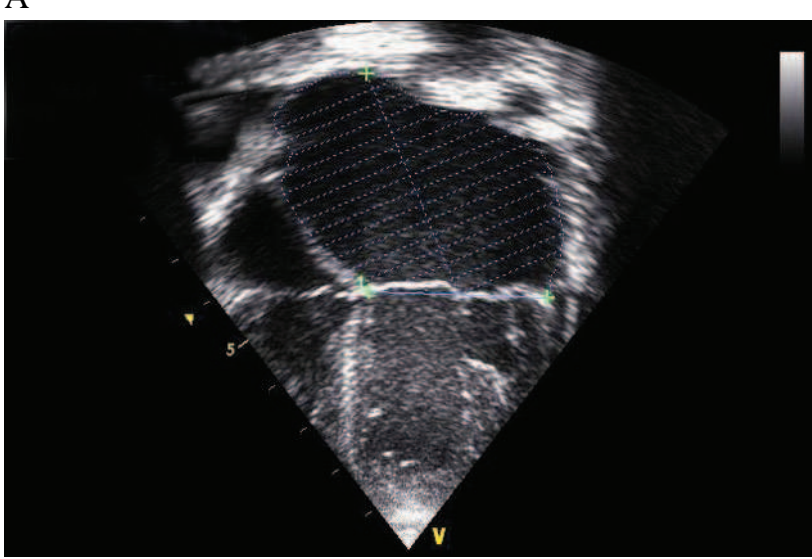

B

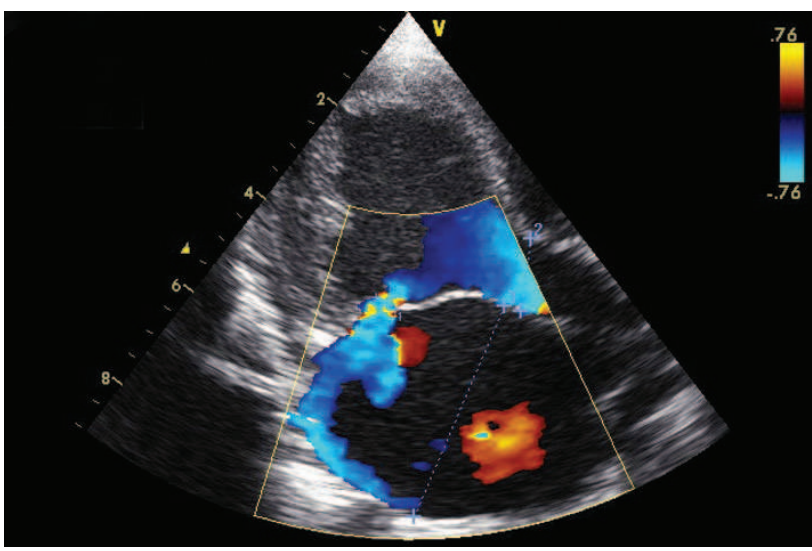

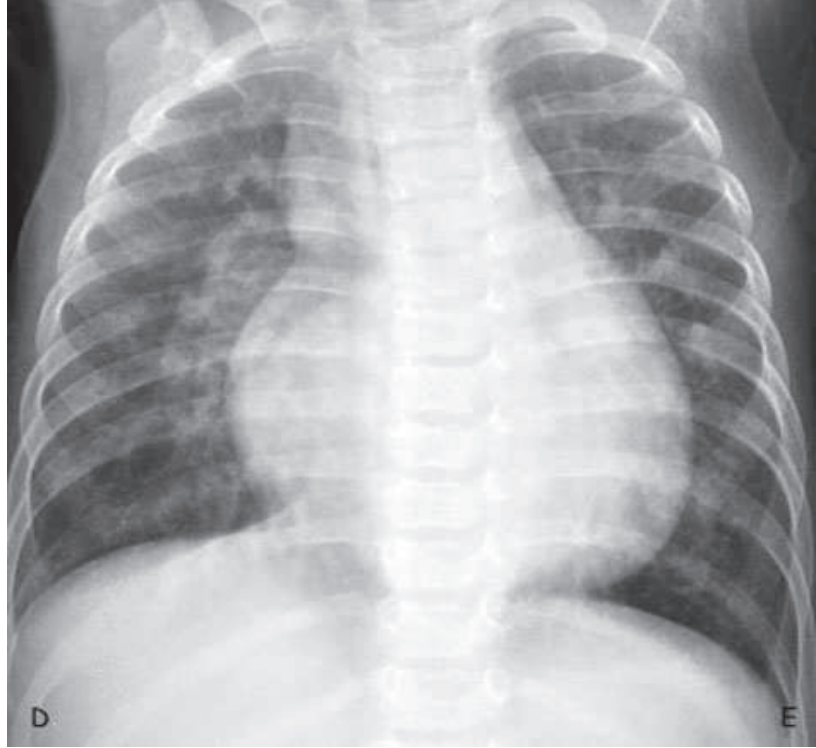

Fig. 2 - Chest radiography with cardiothoracic ratio of 0.61 and increased pulmonary vasculature. $R$ : Right, $L$ : left

C

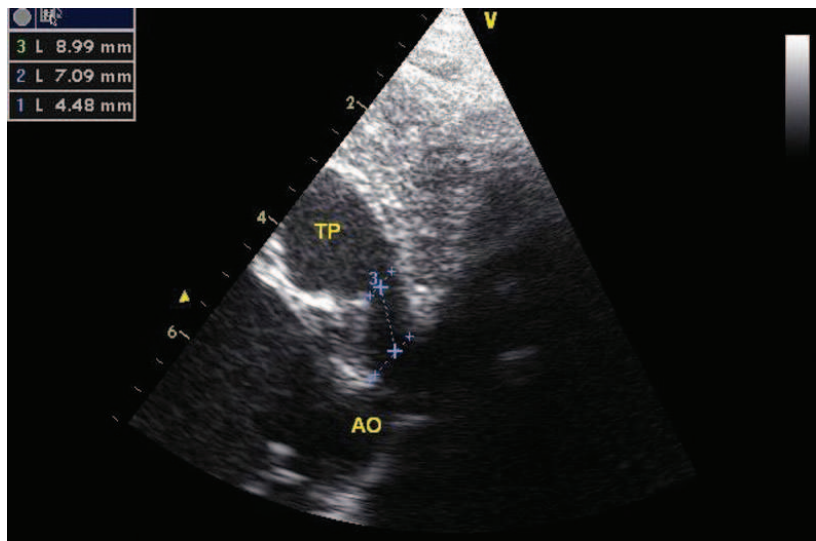

$\mathrm{D}$

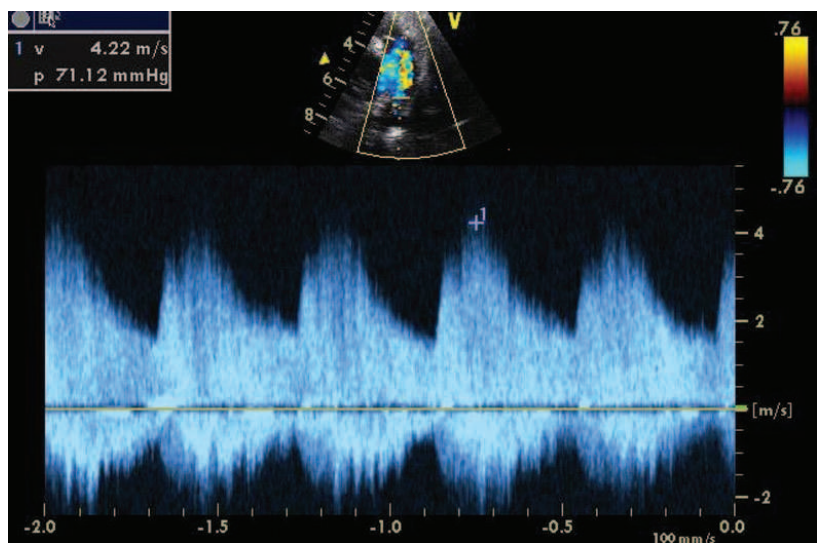

Fig. 3 - (A) Image showing four chambers cut in aneurysmal dilatation of the left atrium. (B) Doppler flow by color with moderate mitral regurgitation. (C) Measures of the patent ductus arteriosus, length (8.99 mm) and aortic (7.09 mm) and lung (4.48 mm) ends. (D) Flow through the ductus arteriosus gradient between the aorta and the pulmonary artery of $71.12 \mathrm{mmHg}$ 


\section{DIAGNOSIS}

The clinical condition was compatible with the acyanogenic congenital heart disease with increased pulmonary blood flow, but not so usual effects of PDA in volume overload of the left chambers were potentiated by the presence of mitral valve prolapse with significant regurgitation. There is a clear indication of late immediate surgical treatment with echocardiographic monitoring aspect of the left atrium and mitral valve function [1,2].

\section{SURGERY}

During monitoring, it was possible to observe the clinical symptoms, with significant bulging chest to the left (Figure 4). The operation was performed routinely by left posterolateral thoracotomy, small incision, opening the parietal pleura, dissection of the PDA region close to the aorta, identification of anatomical structures, passing two 4-0 polypropylene threads around the canal, being one at the aortic end and the other at the pulmonary end and strongly bound, interrupting the blood flow passage. Suture of the parietal pleura, chest tube and chest closure performed by planes.

The child progressed well and was discharged on the third postoperative day and the echocardiogram revealed significant reduction of mitral valve prolapse and trivial regurgitation.

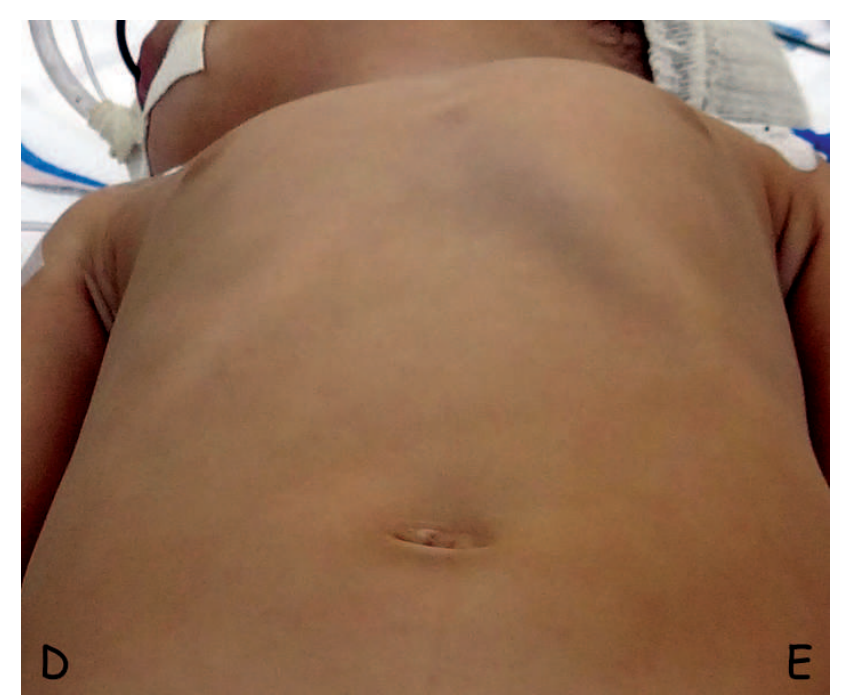

Fig. 4 - Important left bulging chest by an enlarged cardiac silhouette due to aneurysm of the left atrium associated with patent ductus arteriosus with mitral valve prolapse. R: Right, L: left

\section{REFERENCES}

1. Zonnenberg I, de Wall K. The definition of a haemodynamic significant duct in randomized controlled trials: a systematic literature review. Acta Paediatr. 2012:101(3):247-51.

2. Schneider DJ, Moore JW. Patent ductus arteriosus. Circulation. 2006;114(17):1873-82. 